\title{
A universalização da informação
}

João Pimenta da Veiga Filho

Ministro de Estado das Comunicações do Brasil

\section{Resumo}

Trata das ações preponderantes do Ministério das Comunicações no que se refere a serviços de telecomunicações. Apresenta o Programa Telecomunidade, como importante instrumento na preparação da sociedade brasileira para a era digital. O Programa contempla as áreas de educação, saúde, bibliotecas e segurança pública, promove a conectividade de áreas remotas e de fronteiras de interesse estratégico e propicia, em particular, o acesso de portadores de deficiência física às novas tecnologias.

\section{Palavras-chave}

Universalização da informação; Tecomunicações; Telecomunidade; Educação; Saúde; Biblioteca; Telecomunicação-segurança pública; Portadores de deficiência física - acesso às novas tecnologias.

\section{Information universalization}

\begin{abstract}
This article refers to the main actions of the Ministry of Communications as far as the services of telecommunications is concerned. The Telecommunity Program is presented as an important instrument in preparing the Brazilian society for the digital era. The Program embraces the areas of education, health, libraries and public safeguard. It promotes the connectivity of remote and frontier areas of strategic concerns, and, espacially, propitiates the access of handcaps to the new technologies.
\end{abstract}

\section{Keywords}

Information universalization; Telecommunications; Telecommunity; Education; Health; Library; Public safeguard; Handcaps - access to new technologies.
As telecomunicações se constituem hoje no setor que mais cresce em nosso país. E isto tem sido absolutamente notado. Nós saímos, no início da privatização, de 800 mil telefones celulares para 24 milhões. Na telefonia fixa, em apenas dois anos, nós saímos de 13 milhões de acessos fixos para os quase 40 milhões que temos hoje, sendo mais de 32 milhões em serviço.

Nos próximos quatro anos, teremos pelo menos, em um e em outro serviço, em cada um deles, 60 milhões de aparelhos telefônicos, portanto, 120 milhões de telefones celulares e fixos.

O telefone deixou de ser privilégio dos ricos e passou a ser um bem acessível para todos os cidadãos. Nós vamos ter, em pouco tempo, no Brasil, um sistema de telefonia presente em todos os municípios e em todas as localidades com mais de 100 habitantes. Eu não estou me referindo a cidades, a sedes de municípios, estou me referindo a localidades com mais de 100 pessoas - terão telefonia pública disponível. Terão, portanto, pelo menos, um telefone público, ou mais de um, disponível para seus habitantes. Todas as localidades acima de 300 habitantes, em qualquer ponto do território brasileiro, na mais remota região da Amazônia, terão telefonia domiciliar.

Como no município de São Gabriel da Cachoeira, na própria Amazônia, onde levamos, no final do ano passado, telefonia de boa qualidade a uma escola no ponto mais setentrional do território brasileiro para que crianças pudessem ali ter o primeiro contato com a Internet.

Um pouco antes tinha estado na aldeia Mapuera, dos índios Wai-Wai, no estado do Pará, levando telefones para que pudessem se comunicar com o mundo, porque antes eles tinham de viajar cinco dias de canoa para chegar ao primeiro telefone público.

Por isso, eu quero ressaltar a universalização dos serviços de telecomunicações. Com essa política, nós vamos levar telefones a todos os brasileiros, onde quer que estejam. Este é o mandamento dos contratos e das leis.

Pois bem, mas, por que é tão importante o avanço das telecomunicações para um país que quer se desenvolver? Porque hoje o desenvolvimento passa pela informação. A grande revolução que o mundo está vivendo é a da comunicação. Revolução talvez maior do que as revoluções 
anteriores que a humanidade já viveu. $\mathrm{O}$ país que não conseguir pelo menos estar integrado a este processo ficará abaixo do desenvolvimento. Mas aqueles que conseguirem se colocar melhor certamente poderão superar os demais e ganhar várias casas nesta impressionante corrida do desenvolvimento.

Neste avanço que estamos conseguindo, o Brasil se coloca hoje como um dos pontos de maior interesse do mundo no investimento em telecomunicações. Isto não é apenas porque somos um grande país, isto não é apenas porque o Brasil está iniciando uma venturosa quadra de desenvolvimento, mas isto denota, sem dúvida, o atraso que vivíamos nesta área, porque é exatamente o conhecimento deste atraso que coloca o Brasil como um dos principais países hoje na rota das telecomunicações mundiais.

Estamos, na verdade, iniciando uma nova década de prosperidade. Não devemos esperar que os fatos aconteçam para só festejá-los quando eles forem parte do passado. Devemos ter essa consciência agora. Primeiro, porque a consciência de que o país vai crescer facilitará o crescimento e tornará o crescimento uma idéia convergente. Depois, não há razão para esperar que o crescimento passe para depois festejá-lo. Vamos fazê-lo desde já, desde agora, vamos contribuir para que ele se dê de forma mais efetiva, que seja o maior possível. Mas, sobretudo, vamos reinstalar no Brasil a alegria e o otimismo. $\mathrm{O}$ crescimento não é mais um fato do futuro, um que não chega nunca. O crescimento já é uma realidade. Precisamos ter essa consciência, porque ele será melhor em todos os aspectos.

Nós estamos estimulando a tecnologia brasileira. Nós queremos que o Brasil não apenas seja um grande mercado, mas seja também um grande produtor de bens e de produtos nesta área de telecomunicações. E este esforço começa a dar resultados. O $\mathrm{CPqD}$ - centro de pesquisas e desenvolvimento genuinamente brasileiro - abriu recentemente uma subsidiária no Vale do Silício nos Estados Unidos para lá desenvolver a comercialização dos seus produtos. E tenho a grata satisfação de informar que nossos produtos estão rodando hoje em operadoras americanas, e com grande sucesso.

O que nós queremos é que, nas telecomunicações, as nossas empresas possam fazer a trajetória que fez a Embraer. Que começou pequena, uma empresa brasileira, que quis acreditar, viveu grandes dificuldades e hoje é uma das maiores empresas mundiais em alta tecnologia fabricando aviões de todos os tipos, inclusive aviões a jato.
Mas por que disse tudo isso? Porque quero chegar à Internet. Não se pode falar em Internet, se não tivermos uma grande infra-estrutura. É preciso fazer o que estamos fazendo. Nós estamos levando a telefonia a todos os pontos do território brasileiro. Os contratos e as leis, no Brasil, nesta área, determinam que as operadoras são obrigadas a universalizar os serviços - e quero lembrar que a universalização dos serviços de telefonia no Brasil é muito ambiciosa.

A universalização dos serviços telefônicos subdivide-se em dois grupos: primeiro a universalização decorrente das metas contratuais, que faz com que o Brasil tenha, em pouco tempo, um dos maiores avanços entre todos os países. A segunda parte da universalização é a que estamos iniciando com o Programa Telecomunidade, que utiliza os recursos do Fundo de Universalização dos Serviços de Telecomunicações, o Fust.

Nós estamos recolhendo das operadoras, e não dos usuários, a partir de primeiro de janeiro deste ano, um volume expressivo de recursos que serão destinados à universalização não atendida pelas metas contratuais.

O Programa Telecomunidade será um instrumento importante na preparação da sociedade brasileira para a era digital. O simples acesso ao serviço telefônico, essencial no passado, significa, agora, o acesso à Internet.

A Sociedade da Informação, novo modelo social, será caracterizada pelo acesso de todos à informação a todo tempo, em qualquer lugar, de maneira fácil e econômica, cabendo ao governo estabelecer uma base sólida para permitir o desenvolvimento social na idade da informação.

O que o Telecomunidade vai fazer é garantir a todos os brasileiros o acesso ilimitado ao conhecimento, na educação e nas bibliotecas públicas. O ganho na qualidade de ensino será, assim, incomensurável. Os estudantes aprendem na escola várias formas de se comunicar; agora, com a Internet, vão aprender muito mais.

O Telecomunidade vai mais além. Ele vai garantir o acesso mais rápido e eficiente aos serviços públicos de saúde. Vai sofisticar e simplificar os serviços de segurança em regiões remotas do país e em nossas fronteiras. Vai abrir um incomensurável leque de novas oportunidades e possibilidades aos portadores de deficiência física. Vai levar a informação ao setor rural mais isolado do país, conectando-o com o mundo. 
Enfim, o Telecomunidade usará os recursos do Fundo de Universalização dos Serviços de Telecomunicações na instalação e manutenção de infra-estrutura de telecomunicações e informática, com o consenso de que este é o caminho necessário para difundir o conhecimento, distribuir oportunidades e integrar as comunidades.

O Telecomunidade, lançado em fevereiro pelo presidente Fernando Henrique Cardoso, atua nas áreas da educação, saúde, bibliotecas, áreas remotas e de fronteiras de interesse estratégico, em segurança pública, junto a portadores de deficiência física e ainda junto às populações esparsas - fixadas em área de menos de 100 habitantes - e telefonia rural. Ao quantificar o programa é que podemos sentir sua verdadeira e fantástica dimensão.

Junto com o Ministério da Educação, o Telecomunidade vai informatizar e conectar à Internet todas as escolas do ensino médio e profissionalizantes do país - $13 \mathrm{mil}$ estabelecimentos, com sete milhões de estudantes. E, quando as escolas não estiverem funcionando, o equipamento ficará disponível para acesso pelas comunidades locais.

Em parceria com os ministérios da Ciência e Tecnologia e da Cultura e com o Programa Comunidade Solidária, o Ministério das Comunicações vai criar uma grande rede informatizada de mão dupla e conectada à Internet com mais de quatro mil bibliotecas públicas - federais, estaduais e municipais -, mais de cinco mil bibliotecas do chamado $3^{\circ}$ Setor, que é composto por ONGs, e cerca de 430 centros de difusão cultural(museus) em todo o país.

Por exemplo, uma pequena biblioteca da Amazônia vai poder acessar e receber conteúdos da Biblioteca Nacional e também enviar conteúdos seus, da cultura local, para compor o acervo da mesma Biblioteca Nacional.

O Telecomunidade vai trabalhar com os portadores de deficiência física classificados como carentes pelo Ministério da Previdência. São cerca de um milhão e setecentos mil beneficiários, que receberão, cada um, em sua casa, acesso individual e equipamento de interface adequado a cada tipo de deficiência e um computador conectado à Internet.

Essa mesma ação vai alcançar mais de 13.300 instituições de e para portadores de deficiência, com computadores conectados à Internet. $\mathrm{O}$ Telecomunidade vai gerar o acesso desse público especial às possibilidades que a Sociedade da Informação oferece.
Com o Telecomunidade, as pessoas portadoras de deficiências vão ter acesso à informação, teleeducação, teletrabalho e teleconferências. Se considerarmos o impacto real do acesso à Internet na vida das pessoas, podemos imaginar a sua importância como ferramenta tecnológica de equiparação de oportunidades das pessoas portadoras de deficiência. Será o fim de sua exclusão social.

Todas essas ações já foram deflagradas, junto ainda com o Telecomunidade, que vai atingir as regiões remotas e de fronteiras de interesse estratégico.

No caso da parceria com o Ministério da Saúde, estaremos interligando, em rede e com conectividade, todas as equipes do programa Saúde da Família, as centrais de captação de órgãos e de transplantes, os serviços gerenciais de consulta e, ainda, viabilizando, em todo o país, o Cartão SUS.

Este é um projeto que me encanta especialmente. Com ele, o governo do presidente Fernando Henrique Cardoso está promovendo a mais contemporânea das revoluções, universalizando e democratizando a informação e o conhecimento.

Esse ambicioso programa de universalização do acesso à Internet não se encerra com o Telecomunidade. O objetivo maior do governo federal é fazer com que o Brasil entre no século XXI com condições para usufruir seus avanços. Nós estamos trabalhando para que não se registre no Brasil o fenômeno da exclusão digital. Todos os esforços do Ministério das Comunicações e do governo, como um todo, estão direcionados para que não se crie, em nosso país, o analfabetismo digital. E é nesse sentido que incentivamos a criação do computador popular.

O computador popular foi desenvolvido por encomenda direta do Ministério das Comunicações ao presidente do Conselho Gestor da Internet, professor Ivan de Moura Campos, que o viabilizou junto com uma equipe do Laboratório de Informática da Universidade Federal de Minas Gerais. É um modelo simples, mas extremamente eficiente para o que se propõe, que é o acesso à Internet.

Ele foi concebido para chegar ao consumidor a um preço de duzentos e cinquenta dólares. E nós estamos finalizando gestões que vão possibilitar que ele seja comprado a uma prestação entre vinte e cinco a trinta reais, nunca mais que trinta reais, a princípio com o financiamento popular da Caixa Econômica, mas com reais possibilidades de ser financiado por todas as instituições de crédito e financeiras do país. 


\section{Pimenta da Veiga}

Finalmente, a Empresa Brasileira de Correios e Telégrafos acaba de realizar projeto piloto para possibilitar o acesso à Internet por todo o público de suas agências.

São os Quiosques Eletrônicos, que, até o final do ano que vem, estarão instalados em 6 mil unidades dos Correios em todo o país. Isso significa que todos, absolutamente todos os municípios brasileiros, terão um meio de acesso público à Internet.

É através destes esforços que nós, ao olharmos para trás, podemos projetar o futuro. Temos hoje no Brasil um quadro de 100 mil quilômetros de fibra-ótica espalhados por todas as estradas e pelas cidades brasileiras. Este notável, extraordinário avanço da ciência que faz com que uma fibra de espessura comparável a de um cabelo possa transportar voz e dados que antes exigiam cabos eletromecânicos de espessura milhares de vezes superior. Esta fibra que promove este transporte não é apenas confiável, mas de alta qualidade; viabiliza a universalização do uso da Internet, melhor até que o satélite.

Uma revista de circulação nacional publicou, no final do ano passado, matéria que se chamava "O censo do futuro", prevendo que o Brasil terá, dentro de alguns anos, 30 milhões de usuários de Internet. Com o programa de universalização do acesso à Internet, tenho a convicção de que ultrapassaremos essa meta "futurista". Para ter esta que é uma vantagem comparativa muito grande para o nosso país, nós precisamos fazer, e é isto que estamos fazendo: nós estamos espalhando fibra-ótica, melhorando o sistema satelital e fazendo as ligações urbanas para que todos tenham acesso à Internet.

Internet hoje quer dizer acompanhamento simultâneo do que acontece no mundo, mas não apenas no entretenimento, não apenas na informação contemporânea, mas, mais do que isso. Internet hoje quer dizer conteúdo de conhecimento: o que vai fazer a diferença entre os países do futuro é entre os que têm conhecimento e os que não têm conhecimento. Hoje o caminho do conhecimento é a Internet. Por isso estamos nos dedicando com tanto decoro, modernizando com tanto esforço, para dotar o Brasil desta indispensável infraestrutura.

É importante, aqui, que se faça referência às últimas eleições brasileiras. Dentro da normalidade democrática com a qual a sociedade brasileira está acostumada, acabou de transcorrer mais um período eleitoral. Desta vez, em torno da escolha dos novos dirigentes dos mais de cinco mil e quinhentos municípios brasileiros. Eleição livre, limpa e totalmente informatizada.
Em menos de 24 horas, o Tribunal Superior Eleitoral anunciou o resultado final. Foram apurados quase 110 milhões de votos com baixos índices de abstenção, votos brancos ou nulos. O país demonstrou, assim, que sua vitalidade econômica só encontra paralelo em sua exuberância política. Esta, responsável pela solidez e confiança do Brasil como mercado, como parceiro e como formulador de políticas públicas que estão mudando, também, o perfil do subcontinente sul-americano.

Neste campo, eu quero mencionar outro fato que me impressiona e que também é um indicador deste nível de organização: o sistema de apresentação dos resultados fiscais no Brasil alcançou um índice de informatização também muito raro entre todos os países. As pessoas jurídicas fazem, hoje, as suas declarações de Imposto de Renda $100 \%$ pela Internet. Cem por cento das empresas fazem suas declarações pela Internet. E as pessoas físicas, isto que é o mais importante, já alcançaram a marca de $90 \%$.

Estas informações foram e continuam sendo conduzidas em um ambiente da mais clara transparência. Como não poderia deixar de ser, em um país de inequívoco compromisso com a democracia e com o Estado de Direito. Todo o processo de reforma do Estado passou pela discussão e pelo crivo da sociedade, já que o Congresso Nacional teve participação irrestrita nas deliberações finais em torno das iniciativas do Executivo.

A opção pela economia de mercado, com livre participação de capitais de origem múltipla, não foi apenas uma decisão de governo. Veio como uma nítida manifestação da vontade nacional. O Congresso Nacional aprovou, recentemente, a Lei de Responsabilidade Fiscal, que definiu parâmetros muito rígidos para a administração pública brasileira. Com isto, elevamos definitivamente a qualidade da gestão.

$\mathrm{Na}$ atualidade da gestão pública brasileira, que ostenta a marca do "Estado Regulador", o espírito da transparência e da publicidade fica patente nas constantes audiências públicas, que orientam os atos e os regulamentos das agências reguladoras criadas no contexto das ações que vêm dando face moderna ao governo.

Então, como se vê, o princípio democrático da consulta pública, consulta esta tornada ainda mais eficiente com a popularização da Internet, é prática usual do governo brasileiro, agora, modelado segundo os ditames do Estado regulador, e não mais operacional. 
Mas, se a Internet é conhecimento, se a Internet é informação, se a Internet é entretenimento, a Internet é também uma grande oportunidade de negócios. E é importante salientar como a Internet pode avançar os negócios através do comércio eletrônico. $\mathrm{O}$ Brasil está dando apenas os seus primeiros passos nesta nova era. Existem muitas discussões, muitos projetos, muitas leis que estão sendo votadas. E que eu espero que possam fazer com que o Brasil tenha um grande avanço nesta área.

Assim será certamente, porque o Ministério das Comunicações, além de cuidar dos avanços de infraestrutura para o uso da Internet, tem sob seu comando a grande empresa que deve fazer a entrega destes produtos vendidos no comércio eletrônico.

Porque é preciso sempre lembrar que, se a Internet possibilita um extraordinário avanço na aproximação entre comprador e vendedor, alguns têm de cuidar da entrega dos produtos. E está sobre a administração do Ministério das Comunicações a Empresa Brasileira de Correios, e ali nós estamos acompanhando de perto o avanço do e-commerce no Brasil.

Considerando-se que as comunicações são, atualmente, a principal alavanca no processo de formação de massa crítica, em matéria de negócios, de conhecimento de renda, é evidente que, para o Brasil continuar avançando, faz-se necessário tornar realidades estes programas de investimento.

Estimular e ampliar a concorrência sem descuidar da clareza das regras que balizam a competição. Manter o ritmo de digitalização das redes - inferior a 50\%, em 94, e superior a $80 \%$, nos dias de hoje - e, finalmente, diminuir a carga tributária incidente nas contas telefônicas.

No setor de telecomunicações, a previsão de investimento, entre os anos de 2000 e 2003, é de 43 bilhões de dólares. Deve-se atingir um montante superior a 65 bilhões de dólares no ano de 2005, resultando em uma média anual de quase 11 bilhões de dólares no período.

A cada mês está sendo acrescido à rede, em média, um milhão e meio de novos acessos, entre fixos e celulares. Acredito que esta meta será superada. Porque o Brasil é, hoje, um país em transformação com alto grau de confiabilidade econômica. Tivemos êxito no processo de abertura do grande mercado brasileiro, o segundo maior do continente americano.
As telecomunicações não são, no entanto, o único setor do Ministério das Comunicações em que estamos concentrando esforços no sentido de, cada vez mais, unir o Brasil e ligar os brasileiros. Nós estamos promovendo a universalização dos serviços de radiodifusão, especialmente com as rádios comunitárias, instrumento de imenso valor na difusão local de cultura e formação de cidadania.

Priorizamos, ainda na radiodifusão, a concessão de canais de rádio e televisão comerciais nas regiões que ainda não têm esse serviço.

No início deste ano, inauguramos uma agência dos Correios no município de Rio do Fogo, no Rio Grande do Norte, que era o único dos 5.583 municípios brasileiros que não tinha agência dos Correios.

Realizamos uma fantástica universalização dos serviços postais, com as caixas postais comunitárias, levando os Correios e o endereço postal a realmente todos os brasileiros. E estamos levando o banco postal aos municípios que ainda não contam com os serviços bancários básicos.

Este é o Brasil do século XXI, que se apresenta já hoje como uma inquestionável alternativa para o mundo, mas, sobretudo, para os brasileiros.

Com a grandiosidade de seu território - o quinto do mundo - e a segunda população do mundo ocidental, perdendo apenas para os Estados Unidos, este grande país, que dispõe de um mercado que cativa a todos e que cada vez vai mais integrando novos contigentes de consumidores, deverá ser pólo de um dos mais extraordinários avanços e de suas oportunidades, que todo o planeta virá a conhecer.

O governo do presidente Fernando Henrique Cardoso está derrubando um dos fortes mitos da modernidade e um dos pilares da crítica ideológica à globalização da economia mundial. Este é o significado mais profundo dessa revolução a cabo no Ministério das Comunicações.

Ao avanço tecnológico e à derrubada das fronteiras conceituais que mapeavam o planeta com base em economias nacionais, imputa-se a perversidade da exclusão e do desfrute privilegiado de uma minoria formada pelas elites das nações. 
Ainda há alguns que vêm a alta tecnologia e a economia globalizada como instrumentos de exclusão social - e podem ser, se tratados sem sensibilidade pública ou deixados contaminar com a premissa inquisitorial de que o saber e seus ganhos devem ser resguardados como fonte de enriquecimento do poder, e não do engrandecimento de todo um povo.

Evidentemente, a convicção social-democrática do presidente Fernando Henrique Cardoso não permite esse desvio cognitivo que nos levaria aos séculos passados. E o que se poderá empreender com o Programa Telecomunidade a outras ações deste Ministério para a universalização da informação.
Social-democracia, acima de tudo, significa desenvolvimento com justiça social. E com o audacioso processo de privatização do sistema de telecomunicações - com certeza, nenhum outro programa de desestatização alcançou a amplitude do implementado neste setor estamos assegurando, no Ministério das Comunicações, as condições de desenvolvimento de um dos mais importantes campos da vida contemporânea e ao mesmo tempo garantimos o direito de integração pela comunicação de milhões e milhões de brasileiros, antes excluídos.

Os reflexos dessa revolução marcarão o surgimento de um novo paradigma no país. E é sob a força deste novo paradigma que cairão os mitos que sombreiam a fina tecnologia e a globalização da economia com as brumas da exclusão social. 